\title{
Propagação da grama-seda em função da posição na palhada de cana-de-açúcar e deficiência hídrica
}

\author{
Carlos Roberto de Toffoli ${ }^{1}$, Clara Degli Esposti ${ }^{1}$, Anderson Prates Coelho ${ }^{*}$
}

RESUMO: O objetivo desta pesquisa foi caracterizar o comportamento de Cynodon dactylon quando disseminado por diferentes formas em relação à posição na palhada na cultura da cana-de-açúcar, bem como avaliar o efeito do período de seca na capacidade propagativa desta planta daninha. Na primeira parte do experimento, estolões de $C$. dactylon foram colocados em condições: ausência de palhada (T1), sobre a palhada (T2), sob a palhada e em contato com o solo (T3) e entre a palhada de cana-de-açúcar (T4). Um segundo ensaio foi realizado visando verificar o efeito da seca na capacidade propagativa de estolões de $C$. dactylon, com 5 períodos de supressão hídrica (0, 15, 30, 45 e 60 dias) e 3 condições dos estolões no solo (sem palhada, entre a palhada e sob a palhada). Nos dois experimentos foram avaliados: número de estolões viáveis, massa seca da parte aérea e raiz. A brotação de $C$. dactylon não diferiu quando os estolões estavam sem (T1) e sob a palhada (T3). No entanto, a presença da palhada diminuiu significativamente a matéria seca da parte aérea e da raiz. Sob deficiência hídrica, nas condições de ausência, sob e entre a camada de palha, os estolões de $C$. dactylon não se desenvolvem.

Palavras-chave: alelopatia, crescimento, cana-crua, sombreamento

\section{Propagation of bermudagrass according to the position in sugarcane straw and water deficit}

\begin{abstract}
The objective of this research was to characterize the behavior of $C$. dactylon when disseminated by different ways in relation to the straw position in the sugarcane crop, as well as to evaluate the effect of the drought period on the propagation capacity of this weed. In the first part of the experiment, stolons of $C$. dactylon were placed under different conditions: absence of straw (T1), on the straw (T2), under straw and in contact with soil (T3) and between the sugarcane straw (T4). A second experiment was carried out to verify the effect of drought on the propagation capacity of $C$. dactylon stolons, with 5 water suppression periods $(0,15,30,45$ and 60 days) and 3 soil stolon conditions (without straw, between the straw and under the straw). In the two experiments were evaluated: number of viable stolons, matter dry mass and root. Sprouting of $C$. dactylon did not differ when stolons were without (T1) and under straw (T3). However, the presence of straw decreased significantly the dry matter of shoot and root. Under water deficiency, under the conditions of absence, under and between the layer of straw, stolons of $C$. dactylon do not develop.

Keywords: allelopathy, cane-raw, growth, shading
\end{abstract}

\section{INTRODUÇÃO}

A cana-de-açúcar é a terceira cultura mais plantada no Brasil, com área de $9,0510^{6}$ ha, ficando atrás somente da soja e do milho (CONAB, 2017). Como é uma cultura que apresenta cortes anuais, o seu desenvolvimento inicial é lento e, devido ao espaçamento de plantio, problemas com plantas daninhas são sérios nos canaviais, chegando a $60 \%$ de perdas na produtividade (GALON et al., 2011). Além disso, o período para o controle das plantas infestantes é longo, uma vez que a interferência por água, luz e nutrientes é crítica entre os 18 e 188 dias após a brotação (MEIRELLES et al., 2009; BRESSANIN et al., 2016).

Sabe-se que o plantio, operações de quebralombo, cultivo e colheita da cana-de-açúcar são rotinas agrícolas importantes realizadas praticamente o ano todo nas diferentes regiões produtoras do país. No entanto, essas práticas têm contribuído para a disseminação de plantas daninhas (CARVALHO \&
MORETTI, 2010), dentre as quais a grama-seda (Cynodon dactylon L.) ganha destaque, uma vez que fragmentos de estolões são capazes de gerar novas plantas, inclusive sobre a palhada de cana-de-açúcar (VICTORIA FILHO \& CHRISTOFFOLETI, 2004).

Por ser uma espécie de hábito rasteiro, a gramaseda interfere na cana-de-açúcar especialmente pela competição por água e nutrientes. Mesmo sem grande competição por luz, a produtividade da canade-açúcar pode ser reduzida em até $32 \%$ em convivência com a grama-seda (RICHARD JR \& DALLEY, 2007). Espécies do gênero Cynodon, devido à presença de rizomas e estolões, apresentam elevada capacidade de propagação (SANTOS et al., 2008) e difícil controle mecânico (SANTOS et al., 2010). Além disso, a presença das estruturas de reserva dificulta o controle químico, tornando essas espécies tolerantes à algumas moléculas (MACHADO et al., 2008).

\footnotetext{
Recebido em 12/03/2018; Aceito para publicação em 15/10/2018

${ }^{1}$ Universidade Estadual Paulista

*E-mail: anderson_100ssp@hotmail.com
} 
A introdução do sistema de colheita de cana-crua trouxe benefícios para os canaviais, dentre os quais pode-se destacar a redução da infestação das áreas por plantas daninhas (FERREIRA et al., 2010). No entanto, verifica-se que com esse novo ambiente de cultivo, algumas espécies são selecionadas e ganham maior importância para a cultura (KUVA et al., 2007). Sendo assim, é necessário avaliar o efeito da palhada sobre o comportamento das diversas espécies de plantas daninhas.

Nesse contexto, objetivou-se caracterizar o comportamento de Cynodon dactylon L. quando disseminado por diferentes formas em relação à posição na palhada na cultura da cana- de-açúcar, bem como avaliar o efeito do período de seca na capacidade propagativa de estolões desta planta daninha.

\section{MATERIAL E MÉTODOS}

O trabalho foi constituído de duas partes: na primeira foi realizada a caracterização da propagação de $C$. dactylon, simulando dispersão por colhedora ou outros implementos utilizados na canade-açúcar em relação a posição na palhada e na segunda parte foi estudado o período de seca na capacidade de propagação de estolões de $C$. dactylon. Os experimentos foram conduzidos em casa de vegetação na Estação Experimental da Herbae, no município de Jaboticabal, São Paulo. A área é localizada a $21^{\circ} 16^{\prime}$ de latitude sul, $48^{\circ} 18^{\prime}$ de longitude oeste e $602 \mathrm{~m}$ de altitude. $\mathrm{O}$ solo foi coletado na camada de $0-0,20 \mathrm{~m}$, com a análise química e granulométrica apresentada na Tabela 1 .

A primeira etapa iniciou-se em 17/05/2014, com o enchimento das caixas e a distribuição de 15 estolões de $C$. dactylon por caixa, sendo finalizado no dia 26/08/2014 com a coleta da parte aérea e raiz para determinação de massa seca e contagem do número de estolões viáveis. Cada parcela foi constituída por uma caixa de polietileno com dimensões de $0,4 \mathrm{~m}$ de comprimento por $0,3 \mathrm{~m}$ de largura e $0,25 \mathrm{~m}$ de altura $\left(0,03 \mathrm{~m}^{3}\right)$, disposto no delineamento em blocos inteiramente casualizado, com quatro tratamentos e seis repetições.

A terra foi previamente peneirada e distribuída na mesma quantidade $\left(0,03 \mathrm{~m}^{3}\right)$ para todas as caixas. Foram coletadas partes propagativas de $C$. dactylon nas proximidades da Estação, em local desprovido de qualquer manejo cultural e/ou químico. Cada parte propagativa foi composta de um estolão com ausência de folhas, contendo $0,20 \mathrm{~m}$ de comprimento e três gemas. As caixas foram molhadas diariamente para proporcionar condições favoráveis para o desenvolvimento da grama-seda.

O trabalho foi constituído por 04 tratamentos. No tratamento 1 (T1) houve a distribuição dos estolões diretamente sobre o solo, não havendo presença de palha. No tratamento 2 (T2), a distribuição dos estolões ocorreu sobre a palha, assim fixando uma barreira orgânica entre os estolões e o solo. O tratamento 3 (T3) foi determinado com a disposição dos estolões no solo e cobertos com camada de palha, desse modo os estolões estavam em contato direto com o solo mas com o sombreamento causado pela camada de palha. No tratamento 4 (T4) houve distribuição de metade da camada de palha e acondicionamento dos estolões, em seguida distribuiu o restante de palha, de forma que os estolões ficassem numa faixa entre a palha.

A segunda etapa iniciou-se em 11/10/2014, com o enchimento das caixas com terra e a distribuição de 15 estolões de $C$. dactylon nas caixas, sendo finalizada no dia 11/01/2015 com a coleta da parte aérea e raiz para determinação de massa e contagem do número de estolões viáveis. $\mathrm{O}$ experimento foi instalado em esquema fatorial $5 \times 3$, consistindo de cinco períodos de déficit hídrico $(0,15,30,45$ e 60 dias), e três disposições dos estolões de grama-seda nas caixas (sem palha, entre palha e sob palha), totalizando 15 tratamentos. A lâmina de água aplicada foi de $30 \mathrm{~mm}$ antes da distinção de cada tratamento. Para o tratamento sem déficit hídrico (0 dias), uma lâmina de $5 \mathrm{~mm}$ foi aplicada diariamente. Utilizou-se o delineamento de blocos inteiramente casualizados, com quatro repetições. Cada parcela foi constituída por uma caixa de polietileno com dimensões de $0,34 \mathrm{~m}$ de comprimento por $0,53 \mathrm{~m}$ de largura e $0,20 \mathrm{~m}$ de altura $\left(0,036 \mathrm{~m}^{3}\right)$.

$\mathrm{O}$ volume de palha, por caixa, foi equivalente a 12 toneladas de matéria seca por hectare, quantidade comumente encontrada no cultivo de cana-de-açúcar com colheita mecanizada. Para evitar perda da palha por ação do vento, utilizou-se como proteção das caixas uma tela de arame com malha de $2,5 \mathrm{~cm}$, fio 16.

Para os dois experimentos as avaliações foram: Contagem de números de estolões brotados; Determinação da massa seca da parte aérea; Determinação da massa seca de raiz. Para a determinação da massa seca as plantas foram lavadas e colocadas em estufa com circulação forçada de ar a $70^{\circ} \mathrm{C}$ por 72 horas. Os dados obtidos foram submetidos à análise de variância pelo teste $\mathrm{F}$ e as médias comparadas pelo teste de Tukey ao nível de $5 \%$ de probabilidade de erro. 
Tabela 1. Resultado da análise química e granulométrica de uma amostra composta de solo coletada no local do experimento.

\begin{tabular}{|c|c|c|c|c|c|c|c|c|c|}
\hline $\mathrm{pH}$ & $\mathrm{P}$ resina & M.O. & $\mathrm{K}$ & $\mathrm{Ca}$ & $\mathrm{Mg}$ & $\mathrm{H}+\mathrm{Al}$ & SB & CTC & V \\
\hline $\mathrm{CaCl}_{2}$ & $\mathrm{mg} \mathrm{dm}^{-3}$ & $\mathrm{~g} \mathrm{dm}^{-3}$ & \multicolumn{6}{|c|}{$\mathrm{mmol}_{\mathrm{c}} \mathrm{dm}^{-3}$} & $\%$ \\
\hline 5,2 & 15,0 & 16,0 & 1,9 & 22,0 & 13,0 & 21,0 & 36,9 & 57,5 & 64,0 \\
\hline \multicolumn{3}{|c|}{ Argila } & & Silte & & \multicolumn{3}{|c|}{ Areia total } & Classe textural \\
\hline
\end{tabular}

\begin{tabular}{rc}
$\mathrm{g} \mathrm{kg}^{-1}$ \\
\hline 325 & 65 \\
\hline
\end{tabular}

\section{RESULTADOS E DISCUSSÃO}

$\mathrm{Na}$ ausência de palhada sobre o solo (T1), todos os estolões de $C$. dactylon apresentaram brotação (Tabela 2). No entanto, a brotação sem palha sobre o solo não diferiu $(\mathrm{p}<0.05)$ do tratamento $\mathrm{T} 3$, em que os estolões foram colocados sobre o solo mas com a camada de palha sobre eles. Dessa maneira, verificase que a palhada de cana-de-açúcar não afeta a brotação dos estolões de $C$. dactylon. Para os tratamentos com os estolões entre (T2) e sobre a palhada (T4) a brotação foi estatisticamente inferior ( $<<0.05)$, apresentando reduções de $83 \%$ e $35 \%$, respectivamente.

Tabela 2. Número médio de brotações, matéria seca da parte aérea e matéria seca da raiz das plantas de grama-seda $(C$. dactyon) em função da disposição na palhada de cana-de-açúcar.

\begin{tabular}{ccccccc}
\hline Trat. & \multicolumn{2}{c}{ Média de brotações } & \multicolumn{2}{c}{ MS $(\mathrm{g})$ parte aérea } & \multicolumn{2}{c}{ MS $(\mathrm{g})$ raiz } \\
\hline $\mathrm{T} 1$ & 15,0 & $\mathrm{a}$ & 78,6 & $\mathrm{a}$ & 68,0 & $\mathrm{a}$ \\
$\mathrm{T} 2$ & 2,5 & $\mathrm{c}$ & 10,7 & $\mathrm{c}$ & 3,9 & $\mathrm{c}$ \\
$\mathrm{T} 3$ & 13,3 & $\mathrm{a}$ & 25,6 & $\mathrm{~b}$ & 26,2 & $\mathrm{~b}$ \\
$\mathrm{~T} 4$ & 9,8 & $\mathrm{~b}$ & 22,5 & $\mathrm{bc}$ & 14,8 & $\mathrm{bc}$ \\
\hline
\end{tabular}$$
\mathrm{F}
$$

$74,32 * *$

$90,19 * *$

$44,54 * *$

$\mathrm{CV}(\%)$

16,0

23,0

36,0

ns - não significativo pelo teste $\mathrm{F}(\mathrm{p}>0,05) ; * \mathrm{e}^{* *}$ significativo pelo teste $\mathrm{F}(\mathrm{p} \leq 0,05$ e $\mathrm{p} \leq 0,01$, respectivamente). Médias seguidas pela mesma letra na coluna não diferem entre si pelo teste de Tukey a 5\% de probabilidade. T1-sem palhada; T2-sobre a palhada; T3-sob a palhada; T4-entre a palhada

Verifica-se que mesmo deixando $100 \%$ da palha da cana-de-açúcar no campo após a colheita, a infestação por grama seda não é totalmente controlada (OLIVEIRA \& SIMÕES, 2014). Isso ocorre devido à presença de estruturas que armazenam energia para a planta como os estolões. A energia extra presente nessas estruturas auxilia as plantas na emissão de raízes e parte aérea e, consequentemente, na sua dispersão (MACHADO et al., 2008). Dessa maneira, mesmo em ambientes sombreados, plantas que apresentam reservas de

\begin{tabular}{llc}
\multicolumn{2}{r}{610} & \multicolumn{2}{c}{ Média } \\
$\begin{array}{l}\text { energia como } \\
\text { desenvolver. }\end{array}$ & a grama-seda, conseguem se
\end{tabular}

Para a matéria seca da parte aérea, a palhada de cana-de-açúcar causou decréscimos significativos $(\mathrm{p}<0.01)$ em relação à testemunha sem palha. A diminuição do acúmulo de massa foi de $86 \%, 67 \%$ e $71 \%$ para os tratamentos sobre a palhada (T2), sob a palhada (T3) e entre a palhada (T4), respectivamente. Além disso, embora a média de brotações do tratamento $\mathrm{T} 3$ tenha sido superior à do tratamento $\mathrm{T} 4$, não ocorreu diferença na matéria seca da parte aérea entre esses tratamentos. Isso ocorre, pois mesmo apresentando menor número de brotações, as plantas do tratamento T4 encontraram melhor ambiente para o seu crescimento, uma vez que a barreira física para elas era inferior à do tratamento T3 após a brotação, encontrando-se entre e não sob a palhada.

$\mathrm{O}$ mesmo fato ocorreu para a matéria seca da raiz, em que o tratamento $\mathrm{T} 1$ apresentou maior massa do sistema radicular $(\mathrm{p}<0.01)$ do que os demais. A redução dessa análise para os tratamentos T2, T3 e T4 foi de 94\%, $61 \%$ e 78\%, respectivamente. Os resultados de matéria seca evidenciam a interferência da presença da camada de palha na propagação dos estolões, os quais, na condição sobre a palhada (T2) apresentaram menor taxa de desenvolvimento.

Diversas espécies de plantas daninhas apresentam redução da massa seca da parte aérea quando colocadas sob a palhada de cana-de-açúcar. No entanto, a germinação e emergência não é totalmente controlada. Para espécies do gênero Euphorbia, verifica-se que $E$. heterophylla apresentou o melhor desenvolvimento sob palhada do que $E$. hyssopifolia e E. hirta, entretanto, todas apresentaram redução da matéria seca sob quantidades crescentes de palhada sobre o solo (FERREIRA et al., 2017). Avaliando o posicionamento de sementes de E. heterophylla e Mucuna cinereum na palhada, Yamauti et al. (2011), observaram que o desenvolvimento inicial e a germinação das plantas são afetados pela quantidade e posição das sementes na palhada, mas não há a supressão total das espécies. $\mathrm{O}$ mesmo foi observado 
para Cyperus rotundus, em que a adição de palha na dose de 5 a $10 \mathrm{t}$ por hectare diminui a biomassa das plantas, com efeito mais pronunciado nas plantas originárias de tubérculos menores, ou seja, com menor quantidade de reservas (NOVO et al., 2006).

A grama-seda não se desenvolveu sob déficit hídrico, independente da presença ou não de palhada (Tabela 3). Para os tratamentos com déficit, mesmo os mais iniciais (15 dias sem fornecimento de água), a brotação de estolões, massa seca da parte aérea e de raiz não existiram. Para o tratamento sem déficit hídrico as médias do número de estolões, massa seca da parte aérea e de raiz seguiu a mesma tendência do primeiro experimento. A grama-seda encontrou melhor desenvolvimento quando colocada sem palhada no solo. No entanto, para a brotação dos estolões, não ocorreu diferença quando a planta estava sem a palha e sob a palha, conforme observado na primeira etapa do experimento.

Tabela 3. Número médio de estolões brotados, massa seca da parte aérea por caixa e massa seca de raiz por caixa em função do número de dias de déficit hídrico e em condições de ausência de palha (SP), entre a palha (EP) e sob a palha (SB).

\begin{tabular}{|c|c|c|c|c|c|c|c|c|}
\hline \multirow{2}{*}{$\begin{array}{c}\text { Déficit (DH) } \\
\text { (dias) }\end{array}$} & \multicolumn{3}{|c|}{ Número médio de estolões (DP) } & \multicolumn{5}{|c|}{ Massa seca da parte aérea (g) (DP) } \\
\hline & SP & EP & SB & SP & & $\mathrm{EP}$ & SB & \\
\hline 0 & 15,0 Aa & $11,8 \mathrm{Ab}$ & $12,8 \mathrm{Aab}$ & 84,0 & $\mathrm{Aa}$ & 12,1 Ac & 26,3 & $\mathrm{Ab}$ \\
\hline 15 & $0,0 \mathrm{Ba}$ & $0,0 \quad \mathrm{Ba}$ & $0,0 \quad \mathrm{Ba}$ & 0,0 & $\mathrm{Ba}$ & $0,0 \quad \mathrm{Ba}$ & 0,0 & $\mathrm{Ba}$ \\
\hline 30 & $0,0 \mathrm{Ba}$ & $0,0 \mathrm{Ba}$ & $0,0 \mathrm{Ba}$ & 0,0 & $\mathrm{Ba}$ & $0,0 \mathrm{Ba}$ & 0,0 & $\mathrm{Ba}$ \\
\hline 45 & $0,0 \mathrm{Ba}$ & $0,0 \mathrm{Ba}$ & $0,0 \mathrm{Ba}$ & 0,0 & $\mathrm{Ba}$ & $0,0 \mathrm{Ba}$ & 0,0 & $\mathrm{Ba}$ \\
\hline 60 & $0,0 \quad \mathrm{Ba}$ & $0,0 \mathrm{Ba}$ & $0,0 \quad \mathrm{Ba}$ & 0,0 & $\mathrm{Ba}$ & $0,0 \mathrm{Ba}$ & 0,0 & $\mathrm{Ba}$ \\
\hline Média & 3,0 & 2,4 & 2,6 & 16,8 & $\mathrm{a}$ & 2,4 & 5,3 & $\mathrm{~b}$ \\
\hline $\mathrm{F}(\mathrm{DP})$ & & $2,66 \mathrm{~ns}$ & & & & $99,02 * *$ & & \\
\hline $\mathrm{F}(\mathrm{DH})$ & & $499,28 * *$ & & & & $341,34 * *$ & & \\
\hline $\mathrm{F}(\mathrm{DP} * \mathrm{DH})$ & & $2,66^{*}$ & & & & $99,02 * *$ & & \\
\hline C.V. (\%) & & 35 & & & & 42 & & \\
\hline
\end{tabular}

\begin{tabular}{|c|c|c|c|c|c|c|}
\hline \multirow{3}{*}{$\begin{array}{c}\text { Déficit (DH) } \\
\text { (dias) } \\
0\end{array}$} & \multicolumn{6}{|c|}{ Massa seca de raiz (g) (DP) } \\
\hline & \multicolumn{2}{|c|}{ SP } & \multicolumn{2}{|c|}{ EP } & \multicolumn{2}{|c|}{ SB } \\
\hline & 78,7 & Aa & 4,7 & Ac & 27,8 & $\mathrm{Ab}$ \\
\hline 15 & 0,0 & $\mathrm{Ba}$ & 0,0 & $\mathrm{Ba}$ & 0,0 & $\mathrm{Ba}$ \\
\hline 30 & 0,0 & $\mathrm{Ba}$ & 0,0 & $\mathrm{Ba}$ & 0,0 & $\mathrm{Ba}$ \\
\hline 45 & 0,0 & $\mathrm{Ba}$ & 0,0 & $\mathrm{Ba}$ & 0,0 & $\mathrm{Ba}$ \\
\hline 60 & 0,0 & $\mathrm{Ba}$ & 0,0 & $\mathrm{Ba}$ & 0,0 & $\mathrm{Ba}$ \\
\hline Média & 15,7 & $\mathrm{a}$ & 0,9 & $\mathrm{c}$ & 5,6 & $\mathrm{~b}$ \\
\hline $\mathrm{F}(\mathrm{DP})$ & \multicolumn{6}{|c|}{$156,82 * *$} \\
\hline $\mathrm{F}(\mathrm{DH})$ & \multicolumn{6}{|c|}{$451,60 * *$} \\
\hline $\mathrm{F}(\mathrm{DP} * \mathrm{DH})$ & \multicolumn{6}{|c|}{$156,82 * *$} \\
\hline C.V. $(\%)$ & \multicolumn{6}{|c|}{36} \\
\hline
\end{tabular}

ns - não significativo pelo teste $\mathrm{F}(\mathrm{p}>0,05) ; \mathrm{e}^{* *}$ significativo pelo teste $\mathrm{F}(\mathrm{p} \leq 0,05$ e $\mathrm{p} \leq 0,01$, respectivamente). Médias seguidas pela mesma letra, maiúscula na coluna e minúscula na linha, não diferem entre si pelo teste de Tukey a 5\% de probabilidade; SP: sem palhada; EP: entre a palhada; SB: sobre a palhada; DH: déficit hídrico; DP: Disposição na palhada.

A tolerância das plantas daninhas ao déficit hídrico é variável de acordo com a espécie. Verificase que espécies que possuem maior controle estomático e com folhas mais estreitas são mais tolerantes à falta de água, no entanto, quando esta é muito prolongada há a morte dos tecidos da planta, inclusive em gramíneas (HU et al., 2010).

\section{CONCLUSÕES}

A brotação de $C$. dactylon não diferiu quando os estolões estavam sem e sob a palhada. No entanto, a presença da palhada diminuiu significativamente a matéria seca da parte aérea e da raiz.

Em condições com presença da palhada, há maior desenvolvimento da planta quando esta está sob a palha.

Sob deficiência hídrica, nas condições de ausência, sob e entre a camada de palha, os estolões de C. dactylon não se desenvolvem. 


\section{REFERÊNCIAS}

BRESSANIN, F. N.; NETO, N. J.; NEPOMUCENO, M. P.; ALVES, P. L. D. C. A. Períodos de interferência de mucuna-preta na cultura da cana-de-açúcar. Ciência Rural, v.46, n.8, p.1329-1336, 2016. DOI: http://dx.doi.org/10.1590/0103-8478cr20150630

CARVALHO, F.T.; MORETTI, T.B. Manejo de plantas daninhas em cana-de-açúcar (Saccharum spp.) cultivada com a operação de quebra-lombo visando à colheita mecanizada. Revista Brasileira de Herbicidas, v.9, n.1, p.1-8, 2010.

CONAB. COMPANHIA NACIONAL DE ABASTECIMENTO. Acompanhamento da safra brasileira: cana-de-açúcar. Primeiro Levantamento, v.2, n.1. 66p. abril/2016. Conab, Brasília. 2016.

FERREIRA, E.A.; PROCÓPIO, S.O.; GALON, L.; FRANCA, A.C.; CONCENÇO, G.; SILVA, A.A.; ASPIAZU, I.; SILVA, A.F.; TIRONI, S.P.; ROCHA, P.R.R. Manejo de plantas daninhas em cana-crua. Planta Daninha, v.28, n.4, p.915-925, 2010.

FERREIRA， D.T.R.G.; SILVA, V.M.; SILVA, I.C.; ARAÚJO NETO, J.C.; SOUZA, R.C.; FERREIRA, V.M. Germinação de três Euphorbiaceae influenciada pela luz e níveis de palhada. Revista Agroambiente On-Line, v.11, n.3, p.215-222, 2017. DOI: 10.18227/19828470ragro.v11i3.3852

GALON, L.; TIRONI, S.P.; SILVA, A.F.DA; BEUTLER, A.N.; ROCHA, P.R.R.; FERREIRA, E.A.; SILVA, A.A.DA. Disponibilidade de macronutrientes em cultivares de cana-de-açúcar submetidas à competição com Brachiaria brizantha. Ciência Rural, v.42, p.13721379, 2012.

HU, L.; WANG, Z.; DU, H.; HUANG, B. Differential accumulation of dehdrins in response to water stress for hybrid and common bermudagrass genotypes differing in drought tolerance. Journal of Plant Physiology, $\begin{array}{lll}\text { v.167, } & \text { p.103-109, 2010. DOI: }\end{array}$ doi:10.1016/j.jplph.2009.07.008

KUVA, M.A.; PITELLI, R.A.; SALGADO, T.P.; ALVES, P.L.C.A. Fitossociologia de comunidades de plantas daninhas em agroecossistema cana-crua. Planta Daninha, v.25, n.3, p.501-511, 2007.

MACHADO, A.F.L.; MEIRA, R.M.S.; FERREIRA, L.R.; FERREIRA, F.A.; TUFFI SANTOS, L.D.; TEIXEIRA FILHO, C.M.; MACHADO, M.S. Caracterização anatômica de folha, colmo e rizoma de Digitaria insularis. Planta Daninha, v.26, n.1, p.1-8, 2008.

MEIRELLES, G.L.S.; ALVES, P.L.C.A.; NEPOMUCENO, M.;P. Determinação dos períodos de convivência da cana-soca com plantas daninhas. Planta Daninha, v.27, n.1, p.67-73, 2009.

NOVO, M.C.S.S.; VICTÓRIA FILHO, R.; LANGBECK, F.M.; LAGO, A.A. Efeito da palha de cana-de-açúcar e do tamanho do tubérculo na brotação e no desenvolvimento da parte aérea de tiririca. Bragantia, v.65, n.1, p.97-107, 2006.

OLIVEIRA, A.R.; SIMÕES, W.L. Manejo de palhada para o controle de plantas daninhas na cultura da cana-deaçúcar. Circular Técnica 106. Petrolina, PE, 2014.

RICHARD JR, E.P.; DALLEY, C.D. Sugarcane response to bermudagrass interference. Weed Technology, v.21, p.941-946, 2007. DOI: http://dx.doi.org/10.1614/WT-07035.1

SANTOS, M.V.; FERREIRA, F.A.; FREITAS, F.C.L.; IKEDA, A.K.; OLIVEIRA, F.L.R.; ROCHA, D.C.C.; LIMA, J.G.; SILVA, F.N.A.; ASSIS, F.G.V. Tolerância do Tifton 85 (Cynodon spp.) e da Brachiaria brizantha ao glyphosate. Planta Daninha, v.26, n.2, p.353-360, 2008.

SANTOS, M.V.; FREITAS, F.C.L.; FERREIRA, F.A.; CARVALHO, A.J.; BRAZ, T.G.S.; CAVALI, J.; RODRIGUES, O.L. Tolerância do Tifton 85 ao glyphosate em diferentes épocas de aplicação. Planta Daninha, v.28, n.1, p.131-137, 2010.

VICTORIA FILHO, R.; CHRISTOFFOLETI, P.J. Manejo de plantas daninhas e produtividade da cana. Visão Agrícola, n.1, 2004.

YAMAUTI, M.S.; BARROSO, A.A.M.; GIANCOTTI, P.R.F.; SQUASSONI, V.L.; REVOLTI, L.T.M.; ALVES, P.L.C.A. Emergência de plantas daninhas em função da posição da semente e quantidade de palha de cana-de-açúcar. Scientia Agraria, v.12, n.2, p.75-80, 2011. 